\title{
TRÊS PEDACINHOS DE CORPOS EM DELEUZE: ÉTICA, POTÊNCIA E TRANSFORMAÇÃO
}

\author{
Fernando Hiromi IONEZAWA \\ Doutorado em Psicologia/Programa de Pós-Graduação da USP \\ fefoyo@yahoo.com.br
}

Resumo: Este trabalho é parte de nossa pesquisa de doutorado em Psicologia e resultado de um caminho de investigação filosófica acerca do tema do corpo na obra de Gilles Deleuze (e Félix Guattari), que vem desde os anos de nossa graduação. Aprofundando nossos estudos sobre o corpo, a partir do estudo teórico das obras deleuzeanas, veio se destacando a noção de que a produção de um corpo é um problema de natureza ética. Se o corpo aparece, no pensamento deleuzeano, ora como encontro de forças, em outros momentos, também aparece como matéria de expressão das diferenças na forma de dobras. Assim, ainda há a noção de que é pelo corpo que se inicia a potência do pensamento, um devir-corpo. Deste modo, com a intenção de esmiuçar a questão ética relacionada ao corpo, apresentamos aqui um traçado conceitual-filosófico que conecta várias partículas de conceitos habitantes do arsenal filosófico de Deleuze.

Palavras-chave: Ética. Corpo. Potência. Deleuze. Devir

\begin{abstract}
This work is part of our search for a doctorate in psychology and result in a philosophical way of research on the topic of the body in the work of Gilles Deleuze (and Félix Guattari), which comes from the years of our graduation. Deepening our studies on the body, from the theoretical study of Deleuze's works, we have been emphasizing the notion that the production of a body is a problem of ethical. If the body appears in Deleuze's thought, sometimes as meeting of forces, at other times, also appears as the expression of the differences as bendings. Thus, there is still a notion that begins the power of thought begins from body, a becoming-body. Thus, with the intention of detailing the ethical issue related to the body, we present here a conceptual-philosophical route that connects several particles of philosophical concepts inhabitants of Deleuze's philosophic arsenal.
\end{abstract}

Keywords: Ethic. Body. Potency. Deleuze. Becoming

\section{Introdução}

A partir dos estudos que vêm sendo realizados desde a nossa iniciação científica, passando pela pesquisa de mestrado e constituindo, agora, nossa tese de doutorado, começamos a perceber que, no pensamento Esquizo de Gilles Deleuze, o conceito de corpo parece ser formado por peças, fragmentos de conceitos outros, espalhados em muitas de suas obras. Com o intuito de potencializar e aprofundar o conceito de corpo presente no pensamento deleuzeano, apresentamos a seguir um possível traçado destas partículas conceituais, farejando o rastro da leitura deleuzeana de três pensadores, que claramente influenciaram a construção de seu arsenal filosófico. Embora não passemos pelo conceito de Corpo sem Órgãos (CsO), sabidamente importante, acreditamos que conquistamos aqui um potente alinhavado conceitual, que pode muito afirmar uma espécie discreta de corporalismo presente no pensamento de Deleuze. 


\section{Corpo insuspeito}

Deleuze encontra em Espinoza um sereno aliado para seu projeto filosófico: a afirmação do pensamento sem representação e mediação. Afirma, "Espinoza o materialista" (DELEUZE, 2002, p. 23). Isso porque se estaria propondo à Filosofia outro início ao pensamento, outro ponto de partida, "um novo modelo" (DELEUZE, 2002, p. 23): o corpo. Como destaca Deleuze, ao nos distanciarmos da intimidade das potências do corpo, tagarelamos (DELEUZE, 2002, p. 24) e acabamos não sabendo de fato qual é sua capacidade. Então, encontraríamos no corpo um novo modelo para a partida do pensamento imanente, na medida em que houvesse uma verdadeira dissolução da precedência ou do domínio entre corpo e espírito: uma des-hierarquização entre corpo e alma. Esta dissolução das precedências significaria também a ausência de causalidade entre corpo e espírito, a qual se daria através de uma manobra muito sutil e específica: a inversão, ou melhor, a transgressão de um princípio moral básico do pensamento, que fazia padecer a alma toda vez que o corpo agisse; e silenciar o corpo em todo movimento da alma.

Em detrimento da causalidade, Deleuze destaca o paralelismo - tudo aquilo que ao corpo acontece, acontece também, em igual intensidade, ao espírito. Tudo o que fosse movimento de paixões na alma, seria paralelamente movimento no corpo. "Nenhuma preeminência, pois, de uma série sobre a outra." (DELEUZE, 2002, p. 24). Diante de uma histórica sobrevalorização da consciência e da alma dentro da Filosofia, a proposta passa a ser o desfazer-se da moral e da hierarquia não mais pela simples inversão dos dominantes e dominados, espírito ou corpo, mas pelo paralelismo entre corpo e alma, o qual permite afirmar que, se há tanto sobre nossa alma que escapa ao saber e domínio que dela temos, igualmente não menos coisas desconhecemos acerca do corpo. Ao invés de simplesmente inverter a moral, colocando o corpo acima do espírito, o que acontece é uma dupla afirmação do insuspeito, do desconhecido, do devir, tanto para a alma quanto para o corpo. Assim, pode-se fazer, tanto do corpo como do espírito, potências sempre germinais de efetivação. A questão é fazer do corpo um início insuspeito e desconhecido para o pensamento, para que o próprio pensamento seja também uma multiplicidade inundada de potências desconhecidas. Não se recai numa diminuição da importância do pensamento em relação à materialidade do corpo, mas, muito diferentemente, traz-se a desvalorização da consciência diante do pensamento. (DELEUZE, 2002, p. 24-25). Opera-se aí, toda uma “[...] descoberta do inconsciente e de um inconsciente do pensamento, não menos profundo que o desconhecido do corpo." (DELEUZE, 2002, p. 25). Assim, quando se afirma um inconsciente profundo, não se diz de uma profundidade pantanosa, submersa sob camadas escuras e cada vez mais interiores ou 
inferiores. Pelo contrário, o profundo diz respeito ao vasto (FERRAZ, 2002, p. 26), ao múltiplo, àquilo que se espalha com tal amplitude e capacidade de variação, que seus limites e bordas escapam ao campo de visão da consciência - uma multiplicidade plana. Pelo mesmo motivo, o desconhecido atribuído ao corpo e ao pensamento não se confunde com a idéia de que existem coisas submersas e ocultadas por véus e ilusões.

Entretanto, até o momento, não fica evidente o porquê de o pensamento e o corpo se equipararem como aquilo que transborda a capacidade da consciência. Não está muito claro o motivo de isso tudo se chamar materialismo. É que, conforme não exista um tronco axiomático ao pensamento, posto que este é também um insuspeito sem forma, o que resta são apenas os encontros entre os corpos. O pensamento só acontece na presença de uma relação entre corpos. Somente se pode ter o pensamento conforme se têm, paralelamente, notícias daquilo que ocorre no encontro do corpo com outros corpos, o que, por fim, faz o pensamento depender das coisas que tocam o corpo. Somente se descobre a potência do pensamento na medida em que, simultaneamente, se descobre a potência dos corpos, num dado encontro entre estes. Não somos capazes de antemão de termos idéia do que somos, posto que idéias são coisas que acontecem ao pensamento segundo os movimentos das paixões no espírito. Porém, as idéias só nos pertencem na medida em que algo nos acontece ao corpo (DELEUZE, 2002, p. 73). "O que nós temos é a idéia do que acontece ao nosso corpo, a idéia das afecções do nosso corpo, e é apenas por tais idéias que conhecemos imediatamente nosso corpo e os demais, nosso espírito e os demais." (DELEUZE, 2002, p. 73).

Deste modo, descobrir um novo início ao pensamento é descobrir o pensamento como produção de encontros entre os corpos. É esta manobra filosófica que libera a imanência para o pensamento. Por isso é que, ao invés de se igualar o pensamento à consciência, se o iguala ao corpo, segundo uma proposição de "adquirir um conhecimento das potências do corpo para descobrir paralelamente as potências do espírito que escapam à consciência." (DELEUZE, 2002, p. 128). Somente o encontro imanente entre corpos pode dizer de sua potência. Assim, um corpo se definiria sempre por uma infinidade de partículas (DELEUZE, 2002, p. 128) e estas partículas não são necessariamente extensivas, ou seja, concretas, embora elas sejam eminentemente reais e físicas. É que estas partículas são as relações de repouso e movimento, velocidade e lentidão que decorrem tão somente do encontro entre os corpos. De outro modo, a definição de um corpo se dá conforme se conhece também sua potência e esta última diz do aumento ou diminuição da capacidade de agir de um corpo, do aumento ou diminuição deste corpo de ser tocado pela vida (DELEUZE, 2002, p. 33). Um corpo não se define, portanto, por sua forma, mas pelos desdobramentos ou movimentos de que é capaz. Por isso dizemos 
que tomar o corpo como modelo para o pensamento é tomar um modelo cinético, (micro)físico. Um corpo se define pelos movimentos de que é capaz. Deleuze exemplifica colocando lado a lado um cavalo de lavoura e um cavalo de corrida: suas potências são diferentes, mas isso só porque são capazes de movimentos distintos. Igualmente potentes, porém, constituídos de potências de diferentes naturezas. A potência de um corpo é dada, não pela sua forma, ou pela categoria a que pertence, mas pelas relações e movimentos que é capaz de estabelecer nos encontros que realiza.

Diz-se, então, que os corpos produzem uns sobre os outros, efeitos, ou afectos. Estes afectos não são sentimentos (afetos), embora estes últimos não deixem de ser um modo específico de afecto. Os afectos são os vestígios que os corpos produzem entre si nos encontros que realizam. (DELEUZE, 1997, p. 156) Estes vestígios são também percepções, idéias, cores, sensações, texturizações. Os efeitos de um corpo sobre o outro constituem, a cada encontro, uma física própria, um jogo de movimentações, o que nos faz conceituar o corpo como "matéria-força", mais do que como "matéria-forma" (ROLNIK, 2004, p. 227).

“Conhecer o mundo como matéria-forma convoca a percepção, operada pelos órgãos dos sentidos; já conhecer o mundo como matéria-força convoca a sensação, engendrada no encontro entre o corpo e as forças do mundo que o afetam." (ROLNIK, 2004, p. 227). Os movimentos de aceleração e repouso, ou de aumento e diminuição da capacidade de ação são eles próprios as partículas que constituem os corpos. Tais partículas não possuem forma e, mesmo assim, possuem uma física própria, a qual é dada pelos movimentos que se constituem nos encontros. O corpo seria, por isso, matéria que não é forma, consistência abstrata que não é metafísica, concretude intensiva que não é idealizada. Constitui-se, então, um materialismo das intensidades dos corpos. Este materialismo, ao tomar o corpo como matéria-força, ou corpo-fluxo, permite que todas as afecções sejam apenas passagens, fluxos, nunca absolutos ou permanentes, mas consistentes. Os afectos se conectam a outros afectos e estes a outros ainda, ou seja, são efeitos, que remetem a efeitos. (DELEUZE, 1997, p. 159). "Por isso é necessário compreender o "efeito" não só causalmente, mas opticamente.” (DELEUZE, 1997, p. 159). Desta vez, o modelo é também óptico, além de físico. Sendo sempre fluxos de forças, os corpos em seus encontros produzem luz e sombras uns sobre os outros. Os afectos nada mais seriam do que as sombras que outros corpos fariam sobre os nossos.

Encontramos, assim, um Deleuze corporalista, que chama para um questionamento ético. O encontro entre os corpos é sempre uma questão de vida, ou um jogo de decisões para a vida, para a alegria ou para a tristeza, para o aumento e diminuição da potência. “Conhecemos um corpo pela sombra que fazem sobre nós, e é por nossa sombra que nos 
conhecemos, a nós mesmos e a nosso corpo.” (DELEUZE, 1997, p. 159). Quais são os afectos que se sente passar pelo corpo e qual a natureza - qual a potência - deste corpo no qual me transformo em tal encontro? Podemos, então, a partir daqui, dizer que sempre há questões éticas quando se fala dos corpos e seus encontros.

Ao trazer o corpo como modelo de pensamento, Deleuze nos convoca a tomar a matéria como matéria-fluxo, ou "carne percorrida por onda nervosa" (ROLNIK, 2004, p. 227). Ao fazer do corpo um puro fluxo, não se nega sua materialidade, mas se extrai de sua efemeridade, outrora condenada ante a eternidade do espírito, a mais delicada e sensível potência. É neste sentido que Deleuze diz nietzscheanamente "[...] o espírito é a idéia do corpo e de nada mais." (DELEUZE, 2002, p. 75). Haveria então, todo "um mecanismo do corpo capaz de nos surpreender" (DELEUZE, 2002, p. 73), uma espécie de gravidade imposta aos acontecimentos e às sensações, que trariam tudo de volta ao corpo e às planícies imanentes, mesmo diante da maior vontade de desprendimento da terra. Seriam sempre de novo as sensações do corpo que retomariam qualquer possibilidade de sensação. Mesmo a sensação de não haver mais corpo seria ela mesma do corpo. (NIETZSCHE, 2003, p. 40). Nada mais, além do corpo, necessitaríamos para pensar, já que ele mesmo seria uma grande multiplicidade, profunda - vasta - aberta e sempre povoada: repleta, mas não completa.

\section{Corpo à vontade}

Para o corpo como aliado do pensamento, a multiplicidade é condição de existência, bem como ser múltiplo depende de manter sempre presente um caráter de abertura. Daí que a grande multiplicidade de um só sentido que Nietzsche atribui ao corpo (NIETZSCHE, 2003, p. 41) não necessita de nenhum tom de completude absoluta, ou de unidade perfeita. Ao corpo, basta ser repleto. Precisamente, isso significa que não se toma o corpo como representação do pensamento, mas como o próprio pensamento em expressão e movimento. Não se tem ao corpo como imagem do pensamento, senão como movimento em si do pensamento em expressão. O pensamento seria o corpo em sua expressão sem imagem - ato puro, sem mediação. Em outras palavras, o espírito seria físico, ou física de forças.

Os corpos são modos, são relações complexas de velocidade e lentidão (DELEUZE, 2002, p. 128-129). Um corpo é sempre uma relação e esta relação sempre um tipo de variação de potência - aumento ou diminuição. Deleuze diz que os encontros podem alimentar ou envenenar os corpos, ou seja, podem compor ou decompor as forças de que são formados os corpos. (DELEUZE, 2002, p. 131) Perguntam-se, assim, quais seriam os encontros e formas de vida de poderiam nutrir e alimentar este corpo. Com isso, traz-se de volta a questão 
do sentido das forças que compõem e se apoderam de um corpo - questão ética. Este sentido, por sua vez, tem a ver com a avaliação que se possa fazer a respeito dos efeitos que se sente num dado encontro (DELEUZE, 2001, p. 6). A questão seria sempre saber quais tipos de força se apoderam de meu corpo, bem como de que maneira exerço minha potência sobre estas forças. É que, se tomamos nosso corpo como uma complexa variação de potências, sem problemas podemos dizer que estas potências são forças que fazem, a cada encontro, o meu corpo.

Deleuze diz que a proposta principal de Nietzsche consiste em introduzir na Filosofia os conceitos de sentido e valor e que esta filosofia do sentido e do valor seria uma "crítica" (DELEUZE, 2001, p. 5), a qual, contudo, não seria o apontamento de faltas morais e sim a diferenciação da natureza - potência - de cada força. Os corpos seriam forças e, como tais, só poderiam afectar e ser afectados por outras forças. "Qualquer força está portanto numa relação essencial com outra força" (DELEUZE, 2001, p. 13), o que faz com que cada força, ou cada corpo, encontre sua afirmação enquanto diferença na relação com outras forças - e não em relação a outras forças. Isso se chama vontade das forças (DELEUZE, 2001, p. 13). Em outras palavras, se em cada encontro se trata de choques entre forças que se afirmam a si enquanto diferenças, ou enquanto forças com sentidos e valores diferentes, então esta afirmação só pode ser chamada de vontade ativa de afirmação, ou vontade de potência. Logo, as forças ou os corpos seriam vontades que encontram seu sentido no choque com outras forças. "O que uma vontade quer é afirmar sua diferença." (DELEUZE, 2001, p. 17). O sentido de qualquer encontro estaria na relação que os corpos, enquanto forças que se afirmam umas sobre as outras, estabelecem entre si, ou seja, o valor de cada encontro estaria em sua potência. Valor e potência seriam, de alguma forma, sinônimos já que diriam da diferença que um encontro entre corpos seria capaz de afirmar, mover, aumentando ou diminuindo a possibilidade de expressão destes corpos. Um corpo potente seria aquele capaz de criar valores, doar valor. Daí a diferença do homem ético para o homem moral: o corpo da ética trata de injetar valores transformadores no mundo, enquanto o homem moral restringe-se a julgar a vida, rebatendo-a sobre ideais celestiais. O corpo de potências generosamente oferta valor à vida e o corpo do poder, da moral, é sovina, vampiriza as forças vitais para rebaixá-la a princípios e pressuposições. Daí que as forças podem ser de duas naturezas - ativas ou reativas -, as quais definem uma "hierarquia" (DELEUZE, 2001, p. 63) das forças.

Esta hierarquia, contudo, não é uma ordem natural, ou uma organização pré-concebida das forças: como dissemos, trata-se da natureza das forças e não de sua naturalização, ou seja, as forças são reativas ou ativas de acordo com a relação que compõem. As forças reativas são 
aquelas que, na relação que constituem, obedecem. Por outro lado, as forças superiores, que exercem domínio, são as chamadas forças ativas. Esta diferenciação, porém, não estabelece um julgamento das forças, mas refere-se a seus modos de funcionamento, sua forma de ação: toda força age, mas pode agir obedecendo ou dominando. Nenhuma força, por isso, deixa de agir, deixa de afirmar uma potência. "Obedecer é uma qualidade da força enquanto tal, e refere-se ao poder do mesmo modo que ordenar...” (DELEUZE, 2001, p. 63-64). A força reativa, portanto, não perde sua força. A diferença está no funcionamento: enquanto as forças reativas tratam de conservar - organizar, manter, registrar e assegurar -, as forças ativas realizam a tarefa de transformar - diferir, devir, revolucionar, mobilizar, inventar.

Mas, diz Deleuze, é muito mais difícil caracterizar as forças ativas, pois seu modo de operação, sua movimentação é essencialmente fugidia à consciência. Novamente se destaca a pequenez da consciência. O que forma a consciência são as forças reativas, isto é, a consciência nada mais é do que sintoma final de um processo, uma agremiação de forças obedientes. Quer dizer, as forças ativas, por sua vez, são de natureza eminentemente corporal e este corpo é inconsciente, sua potência é inconsciente, desconhecida, imprevisível. "A atividade das forças necessariamente inconsciente, eis o que faz do corpo qualquer coisa superior a todas as reações,...” (DELEUZE, 2001, p. 65). Disso decorre que o verdadeiro problema da vida (ou do vivente), composta por estas relações de forças, consiste na descoberta da potência das forças ativas, consiste na descoberta daquilo que, no corpo, ultrapassa a organização e manutenção estabelecidas pelas forças reativas. O ativo é o que tende à apropriação, ou seja, é o corpo que tende a criar, ativar e transformar. Assim, é somente a partir do ativo, desta força de criação - "poder dionisíaco" (DELEUZE, 2001, p. 66) - que se pode medir o reativo. O reativo só é determinado em função daquelas forças que, em certa relação, são capazes de criar valores, tornando plástica a realidade dos encontros.

Contudo, há um problema ético complicador. É que as forças reativas podem também sobrepor-se às forças ativas, sem que, para isso, deixem de possuir natureza reativa, obediente e inferior (DELEUZE, 2001, p. 88). Torna-se preciso proteger as forças ativas das reativas (DELEUZE, 2001, p. 89). Assim, a arte de doar valor, de avaliar as relações produzidas pelos corpos se torna bastante complicada, pois nenhum valor é fato, mas afecto. Não se pode apenas afirmar de maneira estanque "está aqui a força ativa, está lá a reativa". A avaliação segundo uma ética das diferenças das forças consiste, por isso, em trazer o ativo como elemento potencial presente em toda força, de maneira que seja a capacidade de diferenciação das forças a medida relativa à atividade/reatividade. Disso que as perguntas restantes a cada composição de corpos são: em tal relação de forças, o corpo que se criou foi capaz de 
metamorfosear-se a si próprio e aos demais? O que se produziu foi a manutenção ou a invenção de novas relações? É a ampliação da possibilidade de criação que define o corpo ativo e, a dominação, por sua vez, é ainda decorrente desta capacidade, conseqüência desta natureza.

Deste modo, a questão ética que se coloca sempre junto do corpo está relacionada aos tipos de forças ou potências que produzem meu corpo a cada choque com o mundo. Até aqui começamos a compreender a questão ética relacionada ao corpo e aos seus encontros. Vejamos, pois, como o corpo é conceituado também como superfície direta da expressão de potências.

\section{Corpo de origami}

Para o Deleuze encantado por Leibniz, tudo se passa no nível molecular, microscópico. Tudo acontece aos milhares, em bando, em matilha, em corpos vários e variantes, formados, cada qual de inumeráveis partes. Seriam corpinhos decomponíveis, cada um, em corpos menorzinhos ainda, porém, nunca iguais, nunca unos, embora juntos.

O mundo, portanto, seria infinitamente cavernoso, ou seja, haveria sempre mundos e mais mundos mesmo dentro dos menores corpos (DELEUZE, 1991, p. 19), haveria corpinhos e mais corpinhos dentro de todo corpo - uma multidão corpuscular e, além disso, imperceptível, invisível. Pois bem, se já tomamos o corpo como matéria-fluxo, no livro sobre o conceito de dobra, descobrimos que "o mecanismo da matéria é a mola" (DELEUZE, 1991, p. 19) e isso daria testemunho de uma infinita mobilidade e indefinição da matéria. As forças elásticas da mola seriam a potência primeira da matéria e, justamente isso, daria a possibilidade quase ilimitada de fazê-la alterar-se, criando-se dentro dela própria uma multiplicidade de possibilidades, não de formas, mas de movimentos, de fluxos e passagens. É o que explicaria a presença desses milhares de corpinhos, pois cada corpinho seria resultado da atuação multiplicativa destas forças elásticas sobre a matéria. Por isso, a matéria deve ser considerada em função de sua capacidade de variação, a capacidade de ser temporalizada, açoitada pela diferença. Toma-se a matéria, como um contínuo por variação e a presença essencial das forças elásticas na matéria daria também mostras da potência de vida de cada corpo, potência multiplicitária. A mobilidade não seria apenas prova de capacidade de mudança, como também sinal de potência de duração ou de continuação de uma força no tempo.

Paradoxalmente, o eterno não é o que dura, mas aquele que, no tempo, sustenta em si a força para alterar-se e transformar-se em outro (DELEUZE, 2002, p. 80-81). O finito não é o 
que se acaba no tempo, mas aquele que, no tempo, perde a capacidade de entrar em novas relações. Deste modo, a matéria enquanto força elástica teria em si uma espécie de eternidade - não enquanto forma, mas enquanto potência - que lhe conferiria um tipo de relação de amor com a diferença. Talvez uma relação de amor dolorida com o devir - o devir açoita a matéria e esta se permite diferir, cambiar saboreando as curvas e inflexões que é obrigada a fazer. "A matéria-dobra é uma matéria-tempo...” (DELEUZE, 1991, p. 19) “[...] é o par material-força que substitui a matéria e a forma." (Deleuze, 1991, p. 68). Mais precisamente, a mola da matéria não é elástica, mas força plástica. Vemos, então, que tudo se faz através de forças, forças plásticas que são elas mesmas materiais (DELEUZE, 1991, p. 26). A plasticidade da matéria seria capaz de solucionar, bem ao gosto de uma filosofia da diferença, o problema do contínuo e do variante, do uno e do múltiplo. O modelo da matéria enquanto força plástica daria conta de fazer do múltiplo a propriedade primeira daquilo que é inteiro, aparecendo aí, não mais o uno e o diviso, mas a variação como condição de uma potente inteireza da matéria - não mais o múltiplo, e sim a multiplicidade. Seria a mesma questão que colocamos quando falamos do repleto e do completo. Ao invés de uma imagem de cisão entre o diverso e o uno coeso, uma inflexão sutil que faz do diverso apenas a vida contínua de uma força em movimento.

Por isso, lança-se mão do conceito de dobra como sendo a expressão perfeita destas forças plásticas da matéria, ou ainda como expressão em ato da vida. A capacidade de dobragem da matéria seria sua própria potência em ato, sem mediação, sem representação. A potência de dobrar seria o infinito dentro da matéria, percorrendo-lhe não enquanto princípio ou idéia transcendente, mas como força vivente, condição de vida, linha de multiplicação. “A própria potência é ato, é o ato da dobra." (DELEUZE, 1991, p. 37). Daí que, a maneira pela qual a matéria se dobra é que constituiria sua textura, ou sua potência, ou sua natureza, pois esta textura "define-se menos pelas suas partes heterogêneas e realmente distintas do que pela maneira pela qual essas partes tornam-se inseparáveis em virtude de dobras particulares." (DELEUZE, 1991, p. 70). Por isso, as dobras e as conexões entre elas, que seriam também outras dobras, constituiriam a inteireza e a força de um sentido na matéria. "Em relação às dobras de que é capaz, a matéria torna-se matéria de expressão.” (DELEUZE, 1991, p. 70). Tudo se dobraria à sua maneira, cada matéria se dobraria segundo as forças que fosse capaz de expressar enquanto ato de uma potência. Se a matéria é, ela própria, dobra expressiva de uma potência, então não haveria duas superfícies, sendo uma de concepção e outra de expressão. O mundo seria apenas expressão pura, ou atos puros feitos em dobras da matéria 
enquanto forças plásticas e vivas. O mundo "não existe fora de seus expressantes" (DELEUZE, 1991, p. 198) imediatos, o mundo são forças em ato, dobrando.

Assim, se aceitamos uma antiga - e antiquada - definição filosófica de que o corpo seria nossa porção material, podemos simplesmente dobrar esta definição, ao sabermos também que a força desta matéria estaria justamente em sua capacidade de expressão imediata do mundo. Por isso, o corpo seria para nós nossa zona clara de expressão (DELEUZE, 1991, p. 146). A presença do corpo na vida seria a presença necessária das dobras como expressão desta vida. Deleuze destaca algo bastante intrigante: o corpo seria para nós nossa zona clara de expressão porque temos o obscuro em nós. $O$ obscuro em nós traria a exigência de um corpo (DELEUZE, 1991, p. 145). Mas, se até agora se falou de uma filosofia das superfícies e dos encontros de pele, por que se estaria trazendo de volta um certo obscuro, um indecifrável metafísico? Não! Não se trata do obscuro enquanto o profundo escondido nas trevas de uma caverna. O obscuro em nós é o insuspeito, o devir. É o córrego de intensidades que passa sobre a pele, como camada imediata, colada na superfície. Se a expressão acontece nos encontros superficiais dos corpos, se o corpo é uma zona clara de expressão, então as paixões que passam por essa zona são uma espécie de epiderme incerta do corpo.

Por isso, trazer o corpo como expressão clara e privilegiada de uma obscuridade não é afirmar a profundidade de uma verdade perdida no escuro metafísico, mas reavivar a incerteza que acontece aos corpos. O obscuro é um acontecimento, um percurso diferencial que vem logo do lado, invadindo lateralmente os encontros, cavando túneis e cavernas para os lados. E é para que estes acontecimentos possam ter terreno de expressão no mundo que se deve produzir um corpo, de forma que uma dobra é expressão direta de um obscuro, o qual acontece ao corpo em seus encontros. "Não é o corpo que realiza, mas é no corpo que algo se realiza, com que o próprio corpo se torna real ou substancial." (DELEUZE, 1991, p. 175). A matéria é um fluxo, portanto, todo dobrado, todo vergado, o corpo é uma folha de papel dobrada. Afirmar o corpo como o obscuro em nós é, precisamente, afirmar a diferença de cada encontro, o corpo é matéria, mas somente a matéria que ele se torna no encontro. Tomarmos o corpo, então, como zona clara de expressão da diferença do encontro, ou seja, como expressão direta do obscuro.

O corpo é, mas é o ser da diferença: o corpo só é na diferença, a partir dela. Corpo é ser, mas é o sendo da diferença no encontro. A partir dessa noção é que o corpo vira campo problemático ético, pois a diferença em que ele se transforma no encontro é a dobra que possibilita potencializar, ou não, tal encontro: seguir a potência enquanto fluxo; ou, ao contrário, fazer pará-lo transformando-o fulcro fixo. Aquilo em que o corpo se transforma, 
contudo, não é a transformação completa do corpo - pois raramente o corpo muda completamente -, é, por outro lado, uma transformação repleta no corpo. Este olhar de origamista sobre o corpo convida a mobilizar o pensamento como fluxo direto, imediato, convida a tratar a diferença sem mediá-la, ou melhor, tomar o corpo enquanto diferença dos encontros. Os afectos são potências sem necessidade de mediação, são positividade não terceirizada. Não um imediatismo - forma capitalística de imprimir movimento -, mas um amediatismo. As dobras do corpo são elas próprias suas potências expressas em ato.

Ao se a-mediatizar a diferença no corpo, se faz dele um corpo sempre para a diferença, quer dizer, é sempre pelo corpo que sabemos o que nos acontece, é no corpo que sentimos as transformações que nos ocorrem. O corpo é que traz os verdadeiros problemas ao pensamento, o corpo é diferença imediata para todo o pensar. Se o pensamento só se move “coagido" ou "forçado" (DELEUZE, 2006, p. 247), é porque ele precisa do corpo como aquilo que primeiro lhe afecta. $\mathrm{O}$ corpo seria, por isso, afecto diferencial para o pensamento, a dobra que vem do lado, para devir o pensar. O corpo verga o pensar, imprimindo devires sobre ele, sendo o corpo, ele próprio, veículo catalisador dos devires. Quando o pensamento difere, é o corpo que antes dobrou, curvou-se na diferença.

\section{Conclusão: o devir-corpo na realidade}

Destarte, vamos percebendo que toda vez que se produz um corpo, se está às voltas com um problema ético, quer dizer, todo corpo coloca em questão sentidos, diferenças, valores, realidades, territórios. Um corpo produzido é questão de produção de transformações e potencializações para a vida e, por isso, questão ética. Os componentes constituintes desta problemática ética poderiam ser assim assinalados:

a) Um corpo é problema para o pensamento: a produção de um corpo envolve um problema, uma questão sobre a qual mover o pensamento, sobre a qual fazer o pensamento diferir, pois é a partir das afecções criadas nos encontros que se pode pensar, que se força o pensamento. O corpo faz diferir o pensamento.

b) O corpo é já e sempre pensamento: não é que o corpo seja também pensamento, segundo uma fórmula moral, que caridosamente concederia ao corpo, ou reconheceria nele, capacidade pensante também. Mais radicalmente, só há pensamento porque o corpo é o pensamento, ou melhor, pensamento é corpo e nada mais. Cada corpo produzido é ele próprio um pensar, um gesto, um movimento de 
músculos ou de fluidos é pensamento. Uma cãibra é um pesnamento-acontecimento, que acontece aos nadadores e dançarinos.

c) Um corpo é diferença: a partir de um encontro entre corpos, sempre se produz diferença, um corpo outro, constituído de diferenças, sempre há a produção de uma série de afectos inesperados, inéditos. O corpo produz novidades intensivas, ou intensas novidades.

d) As dobras do corpo são elas próprias diferenças: o corpo é campo de expressão ou passagem - das diferenças de um encontro. É nele que a diferença se torna real e concreta. As mudanças tissulares, articulares, fisiológicas, as mudanças de movimento são imediatas expressões da diferença.

e) No corpo tudo é somente afirmação: o corpo, composto de forças, é ele próprio a ação imediata e concreta destas forças. O corpo, assim, afirma essas forças na realidade, sendo ele próprio as forças em ação. Por isso, nada nele é negação, tudo é vontade, afirmação de forças, é vontade de afirmação.

f) A capacidade de dobragem do corpo o faz parceiro do pensamento: quer dizer, se por um lado, o corpo coage o pensamento a se mover, por outro ele é íntimo e leal amigo do pensamento. É que a plasticidade do corpo enquanto corpo-fluxo desvia-o de ser substância, para ser consistência, tornando esta natureza também possível ao pensamento.

g) O corpo é uma tripla simultaneidade: um corpo, num mesmo golpe, produz diferenças, é superfície de expressão delas e se torna estas diferenças, não porque as encarna, à maneira de um receptáculo, mas porque ele se transforma nas diferenças do encontro.

h) Corpo é potência, um devir-corpo que acontece à realidade: por último, dizemos que a produção de um corpo é sempre produção de uma potência, sempre afirmação de uma potência. Assim, poderíamos dizer que existe um devir-corpo que acontece à realidade. É que, se é ao passar pelo corpo que a diferença se realiza, então, inversamente, é um corpo que acontece à realidade. Existiria um devir-corpo como um potente componente de alteração da realidade. Seria um componente de abertura concreta de lagos de diferença no real. Um devir corporal que faria cortes e interrupções no fluxo estável da realidade para criar-lhe ilhotas de potência e diferença. Além disso, tomando o corpo como vontade em ação, temos um devircorpo que faz frente de combate a todo mentalismo, a toda sobrevalorização da consciência, da razão. Devir-corpo para combater a abstração metafísica e o 
idealismo transcendente. Nada melhor que a imprevisível materialidade plástica do corpo para fazer frente ao racionalismo controlador de nossa constituição cultural. Assim, seriam sempre devires-corpo, muitos, minúsculos, múltiplos, vindos em multidão, na forma de uma trupe guerrilheira. Estes devires-corpo, possuem todas as propriedades da matéria enquanto tal, possuem todas as propriedades do corpo material - concretude, consistência, espessura, realidade - sem, contudo, serem de fato extensivos, visíveis. Falando em termos ópticos, os devires-corpo são, tanto quanto qualquer matéria, tanto quanto o próprio corpo, passíveis de serem afectados pela luz, porém, por transparência, quer dizer, eles fazem da luz, não sua fonte de visibilidade, mas de sua transversalidade. Quanto mais deixam que a luz flua como fluxo, sem refleti-la, tanto mais transparente são e, portanto, tanto mais bem definidos em sua claridade, mais lúcidos. E esta transparência dos devires-corpo compõem com sua massa e espessura, uma nitidez paradoxal, ou seja, transparente quer dizer também, franco, explícito, aquilo que se faz presente por força própria e não se deixa representar, não permite terceirizar sua potência. Portanto, paradoxalmente, os devires-corpo têm peso e materialidade próprias, mas são invisíveis e imperceptíveis, pelo fato de serem uma pura ou infinita translucidez, infinita transparência. Uma franca intensidade. É um canto de mulher que não se escuta, mas se pode apalpar; uma cor de um desenho de criança que só se percebe ouvindo ou sentindo vibrar na pele. Potente consistência que acontece ao real, inclusive ao corpo, porque mesmo o corpo precisa devir-corpo, devir afectos insuspeitos. Os devires-corpo precisam acontecer ao corpo.

Neste sentido, o devir-corpo é uma espécie de vazio-cheio, na qual a única ausência é a da mediação e da transcendência. Corpo ausente, mas ausente da transcendência, do ideal. Quando ao corpo acontece um devir-corpo é porque ele foi esvaziado de qualquer mediação dos encontros e, então, mesmo a relação com uma ferramenta é a-mediata, não havendo nenhuma forma de interposição entre a vontade, o corpo e o ato, ou entre mundo e corpo. O devir-corpo é, ainda, o corte de Shiva, deus indiano da destruição necessária a toda transformação. Quando tudo pára é que pode começar a mover-se. O mundo, desta vez, é devolvido à sua coletividade e multiplicidade, porque, concomitantemente, devolve-se o corpo ao mundo, ou o mundo ao corpo. Nos encontros entre os corpos os devires-corpo açoitam o real com a diferença e produzem imperativos de transmutação, os quais, entretanto, são imperativos internos à complexidade dos encontros entre os corpos, exigências 
impelidas tão somente pela vontade de potência. Não são leis transcendentes, imperativos externos. Desta forma, os devires-corpo são os que possibilitam que à realidade caibam novos agenciamentos, novas movimentações, é este o devir que possibilita a transvaloração da realidade. Assim, tomamos a ética como problema da produção de corpos porque é a vida que aí está em jogo. É a expansão ou contração da vida que está em jogo.

O que apresentamos aqui, através do desenvolvimento da idéia de que corpo e ética são questões intimamente conectadas, foi uma espécie de experimentação e vasculha conceitual. É que, sabendo que a Filosofia não serviria para comunicar, refletir ou circunscrever universais, mas para praticar a arte de inventar conceitos (DELEUZE\&GUATTARI, 1992, p. 14) - dentro de uma superfície de imanência da qual se extrai sempre novos e inesperados afectos e perceptos -, nossa pergunta foi: 'qual seria a tarefa prática de uma filosofia do corpo?'. Perguntamo-nos, portanto, qual seria o devir conceitual que, tencionando o conceito de corpo, chegaria como conexão imediata a uma filosofia corporalista. Em outras palavras, questionamos como poderíamos vergar este conceito, dobrá-lo em direção a uma linha de criação.

Contudo, sabemos que um devir conceitual é uma composição, que trabalha sob a noção de que "[...] se tudo é tomado conjuntamente, é por caminhos divergentes" (DELEUZE\&GUATTARI, 1992, p. 35), quer dizer, os conceitos são sempre feitos de partes e ele nada mais é do que uma linha que conjuga estas partes. Sendo assim, os conceitos podem muito bem ter partes fragmentárias vivendo em ressonância entre si, à distância, a partir de regiões distintas de um plano. A questão para nós, por isso, passou a ser a de pinçar estas partes possivelmente ressoantes, de modo que compusessem um novo plano e um devir que fizessem vibrar o conceito de corpo de uma nova maneira "[...] cada conceito remete a outros conceitos, não somente em sua história, mas em seu devir ou suas conexões presentes." (DELEUZE\&GUATTARI, 1992, p. 31). Tratamos, portanto, de formular, para as partículas conceituais relacionadas ao tema do corpo na obra de Deleuze, uma linha de composição possível, cuja montagem foi, evidentemente, artificial. Com isso, porém, esperamos ter conquistado um efeito de potência absolutamente genuíno. Afinal, como diz o poeta Manoel de Barros, "tudo o que não invento, é falso" (BARROS, 2003, p. 2). 


\section{Referências}

BARROS, M. Memórias Inventadas: a infância. São Paulo: Planeta, 2003.

DELEUZE, G. \& GUATTARI, F. O que é a Filosofia? Rio de Janeiro: Editora 34, 1992.

DELEUZE, G. A Dobra: Leibniz e o Barroco. Campinas: Papirus, 1991.

DELEUZE, G. Crítica e Clínica. São Paulo: Editora 34, 1997.

DELEUZE, G. Diferença e Repetição. Rio de Janeiro: Graal, 2006.

DELEUZE, G. Espinosa: filosofia prática. São Paulo: Escuta, 2002.

DELEUZE, G. Nietzsche e a Filosofia. Porto: Rés-Editora, 2001.

FERRAZ, M. C. F. Nove Variações sobre Temas Nietzschianos. Rio de Janeiro: Relume Dumará, 2002.

NIETZSCHE, F. Assim Falou Zaratustra. São Paulo: Matin Claret, 2003.

ROLNIK, S. "O ocaso da vítima para além da cafetinagem da criação e de sua separação da resistência." in: LINS, D. \& PELBART, P. P. (Orgs.). Nietzsche e Deleuze: bárbaros civilizados. São Paulo: Annablume, 2004. 